Physics International 2 (1): 21-24, 2011

ISSN 1948-9803

C 2011 Science Publications

\title{
Electronegativity, Interaction Parameter and Electronicpolarizability for Bisumth Borate Metal Glasses
}

\author{
El-Sayed Moustafa and Farid Elkhateb \\ Department of Physics, Faculty of Science, \\ Azaher University, Assuit Branch, Egypt
}

\begin{abstract}
Problem statement: In the present work, we applied the concept of the optical electronegativity to predict basic properties of some ternary oxide glasses. Recently Optical electronegativity of many binary oxide glasses has been evaluated on the basis of two different parameters, the linear refractive index and the energy gap, which have demonstrated remarkable correlation. Approach: In this study, the refractive indexhas beendetermined through the optical electronegativity and obtain a perfect linear correlation between the calculated refractive index and the estimated values using the dielectric constant value of the prepared samples. Results: The average electronic oxide polarizability and the interaction parameter of our ternary oxide glasses have been estimated on the basis of the average optical electronegativity. Conclusion: The estimated values are in good agreement with the available experimental data. The present research is an improvement of the optical electronegativity determination.
\end{abstract}

Key words: Electronegativity, interaction parameter, oxide ion polarizability, ternary glasses

\section{INTRODUCTION}

Recently oxide glasses take a considerable attention in view of their potential for use as laser hosts, in fiber and as nonlinear optical materials (Varshneya, 1994; Chimalawong et al., 2010). The studies on glasses of metal oxides are relatively meager due to difficulties in identifying and preparing such glasses although they show interesting electronic and nonlinear optical properties (Vithal et al., 1997). The present work pertains to some new optical parameters in thecase of some ternaryglass systems. (Dimitrov and Sakka, 1996) have shown that for simple oxides, the average electronic oxide polarizability calculated on the basis of two different properties linear refractive index and optical band-gap energy shows remarkable correlation. In the present work we examine whether their observations can be extended to glasses formed from ternary oxides glasses. This is of a particular interest especially when the relevant quantities can be experimentally obtained for glass systems and polarizability values related to glasses are of value for developing glass systems with nonlinear optical properties. To our knowledge an attempt of this kind is being reported for the first time. We chose to $\mathrm{B}_{2} \mathrm{O}_{3}-$ $\mathrm{Bi}_{2} \mathrm{O}_{3}$ glass system for our study, as the oxide ion polarizability for $\mathrm{Bi}_{2} \mathrm{O}_{3}$ is relatively high.
Theoretical considerations: The relative ability of an atom to draw electrons in a bond toward itself is called the electronegativity of the atom. Atoms with large electronegativities (such as $\mathrm{F}$ and $\mathrm{O}$ ) attract the electrons in a bond better than those that have small electronegativities (such as $\mathrm{Na}$ and $\mathrm{Mg}$ ). The electronegativities of the main group elements are given by (Marquez and Rinocon, 2006) introduced the concept of average electronegativity and defined an average electronegativity parameter $\chi_{1 \mathrm{av}}$ in the following Eq. 1 manner:

$\chi_{\text {iav }}=\sum_{i=1}^{N} \frac{n_{i} \chi_{1}}{N}$

Where:

$\chi_{1}=$ The Pauling electronegativity of element

$\mathrm{n}_{\mathrm{i}}=$ The number of atoms of the $\mathrm{i}^{\text {th }}$ element

$\mathrm{N}=$ The number of elements present in the compound

In this connection (Reddy et al., 2001) have derived the following empirical relationship for the average electronic oxide ion polarizability as follows Eq. 2:

$\alpha_{\mathrm{o}-2}=4.624-0.7569 \chi_{\mathrm{av}}$

(C) 2011 El-Sayed Moustafa and Farid Elkhateb. This open access article is distributed under a Creative Commons Attribution (CC-BY) 3.0 license which permits unrestricted use, distribution, and reproduction in any medium, provided the original work is properly credited. DOI: 10.3844/pisp.2011.21.24 
where, $\chi_{1 a v}$ is the average electronegativity of the simple oxide. Reddy et al. (2001) have calculated $\alpha_{02}$ for many oxides and in general there is agreement with previously obtained data by Dimitrov. But it should be mentioned that polarizability of $\mathrm{B}_{2} \mathrm{O}_{3}\left(2.426 \mathrm{~A}^{3}\right)$ and $\mathrm{SiO}_{2}\left(2.419 \mathrm{~A}^{3}\right)$ calculated by Eq. 2 seems to be too large.

Reddy et al. (2001) and Zhao et al. (2007) have applied the electronegativity approach to the same glasses already studied by (Dimitrov and Komatsu, 1999). According to Reddy et al. (2001), the following empirical relations between oxide ion polarizability and average electronegativity is as follows Eq. 3:

$\alpha_{o-2}=4.519-0.3422 \chi_{\text {lav }}$

Another formula for all binary oxide glass compositions except $\mathrm{TeO}_{2}, \mathrm{GeO}_{2}$ and $\mathrm{TiO}_{2}$ as a second oxide also was proposed as follows Eq. 4:

$\alpha_{\mathrm{o}-2}=\left(\chi_{\mathrm{lav}^{-}}-1.35\right) /\left(\chi_{\mathrm{lav}^{-}}-1.8\right)$

where, $\chi_{\text {lav }}$ is the averageelectronegativity of binary oxide glass. On the other hand (Zhao et al., 2007) have introduced the optical electronegativity calculated from the refractive index to predict oxide ion polarizabilityof binary oxide glasses Eq. 5:

$\alpha_{0-2}=3.5-0.9 \chi_{\text {glass }}$

It should be noted that the estimated values of by Reddy et al. (2001) and Zhao et al. (2007) are in good agreement with the refractive index based oxide ion polarizability of the same glasses obtained by (Dimitrov and Komatsu, 2010).

Assuming that molar refractivity $\left(\mathrm{R}_{\mathrm{m}}\right)$ and polarizability $\alpha_{\mathrm{m}}$ are additive quantities (Dimitrov and Sakka, 1996) obtained the relationship Eq. 6:

$\mathrm{R}_{\mathrm{p}}=\mathrm{pR}_{\mathrm{i}}+\mathrm{qR}_{\mathrm{O}^{2-}}=2.52\left[\mathrm{p}_{\mathrm{i}}+\mathrm{q \alpha}_{\mathrm{O}^{2-}}\right]$

Where:

$\mathrm{R}_{\mathrm{i},}=$ Ionic refraction of cation

$\mathrm{R}_{\mathrm{O}}{ }^{2-}=$ The refraction of oxide ion, respectively

$\mathrm{P}$ and $\mathrm{q}$ denote the number of cation and oxide ion in the chemical formula $\mathrm{A}_{\mathrm{P}} \mathrm{O}_{\mathrm{q}}$. This relationship leads to Eq. 7:

$$
\alpha_{\mathrm{o}^{2-}}(\mathrm{n})=\left[\left(\frac{\mathrm{v}_{\mathrm{m}}}{2.52}\right) \frac{\left(\mathrm{n}^{2}-1\right)}{\left(\mathrm{n}^{2}+2\right)}-\sum_{\mathrm{i}} \mathrm{p} \alpha_{\mathrm{i}}\right] \mathrm{q}^{-1}
$$

Another optical parameter used to describe the polarizability state of the oxide ion in the simple glasses called the interaction parameter of the glass is given by (Zhao et al., 2007) as follows Eq. 8:

$$
\begin{aligned}
A & =X_{\mathrm{B} 203} \frac{\left(\alpha_{\mathrm{f}}^{-}-\alpha_{o-2}\right)}{2\left(\alpha_{\mathrm{f}}^{-}+\alpha_{\mathrm{B}+3}\right)\left(\alpha_{\mathrm{o}-2}+\alpha_{\mathrm{B}+3}\right)} \\
& +\mathrm{X}_{\mathrm{Bi} 2 \mathrm{O} 3} \frac{\left(\alpha_{\mathrm{f}}^{-}-\alpha_{\mathrm{o}-2}\right)}{2\left(\alpha_{\mathrm{f}}^{-}+\alpha_{\mathrm{Bi}+3}\right)\left(\alpha_{\mathrm{o}-2}+\alpha_{\mathrm{Bi}+3}\right)}+.
\end{aligned}
$$

where, $\alpha_{\mathrm{f}}^{-}$is the electronic polarizability of the free oxide ion and $\alpha_{0-2}$ correspond to $\alpha_{0-2}(\mathrm{n})$, the interaction parameter has been estimated according to Eq. 8 .

\section{MATERIALS AND METHODS}

The glass samples were prepared using appropriate amounts of grade reagents boron oxide, bismuth oxide and copper oxide, ferrite oxide zinc, Aluminum and Cadmium oxide. The weighted quantities of the starting materials for glass batch corresponding to the glass composition were mixed homogeneously. The mixture was placed in a ceramic crucible and heated slowly in an electric furnace to $1100^{\circ} \mathrm{C}$. The temperature was raised gradually depending upon the glass composition. The crucible containing the melt was constantly agitated to ensure homogeneous mixing. Sufficient time was allowed for the melt to become visibly homogeneous and bubble free. The melt was rapidly quenched to room temperature between two stainless-steel plates. There was no noticeable reaction of the melt with crucible walls. The typical weight loss on melting under the experimental conditions can be neglected with respect to the values quoted for the components. The composition of the glass system was prepared in a series of 6 samples as illustrated in Table 1.

The samples were annealed at a temperature below glass transition temperature and subsequently polished with commercial media and water free lubricant. The glass samples were obtained with a uniform thickness of $4.0-5.0 \mathrm{~mm}$. The dc electrical conductivity of prepared glasses, the polished glass samples were silver painted on both sides and kept in a cell for good contacts. The value of applied voltage $=3.0 \mathrm{~V}$ and the voltage drop across the sample and across a standard resistor were measured. Space-charge effects were minimized by using a very low field, which was applied only briefly. The temperature of the glass sample was measured by a chromel-alumel (the measurements have been carried out at room temperature), thermocouple with an accuracy of $\pm 1 \%$. 
Phy. Intl. 2 (1): 21-24, 2011

Table 1: The prepared samples in mole percent

\begin{tabular}{lll}
\hline 80 & 15 & 5 \\
\hline $\mathrm{B}_{2} \mathrm{O}_{3}$ & $\mathrm{Bi}_{2} \mathrm{O}_{3} 20 \%$ & - \\
$\mathrm{B}_{2} \mathrm{O}_{3}$ & $\mathrm{Bi}_{2} \mathrm{O}_{3}$ & $\mathrm{Fe}_{2} \mathrm{O}_{3}$ \\
$\mathrm{~B}_{2} \mathrm{O}_{3}$ & $\mathrm{Bi}_{2} \mathrm{O}_{3}$ & $\mathrm{CuO}$ \\
$\mathrm{B}_{2} \mathrm{O}_{3}$ & $\mathrm{Bi}_{2} \mathrm{O}_{3}$ & $\mathrm{ZnO}$ \\
$\mathrm{B}_{2} \mathrm{O}_{3}$ & $\mathrm{Bi}_{2} \mathrm{O}_{3}$ & $\mathrm{Al} \mathrm{O}_{3}$ \\
$\mathrm{~B}_{2} \mathrm{O}_{3}$ & $\mathrm{Bi}_{2} \mathrm{O}_{3}$ & $\mathrm{CdO}$ \\
\hline
\end{tabular}

Table 2: Illustrates the calculated values of the average electronegativity, oxide ion polarizability, interaction parameter and the refractive index of the prepared glasses

\begin{tabular}{llllll} 
Type of glass & $\chi_{\text {} \alpha 1}$ & $\alpha_{\text {o2- }}$ & $\mathrm{A}$ & $\mathrm{n}_{\text {calc }}$ & $\mathrm{n}_{\mathrm{m}}$ \\
\hline $\mathrm{B}_{2} \mathrm{O}_{3}-\mathrm{Bi}_{2} \mathrm{O}_{3}$ & 2.59 & 1.700 & 0.1494 & 2.10 & 2.00 \\
$\mathrm{~B}_{2} \mathrm{O}_{3}-\mathrm{Bi}_{2} \mathrm{O}_{3}-\mathrm{CuO}$ & 2.45 & 1.751 & 0.1600 & 1.80 & 1.90 \\
$\mathrm{~B}_{2} \mathrm{O}_{3}-\mathrm{Bi}_{2} \mathrm{O}_{3}-\mathrm{Fe}_{2} \mathrm{O}_{3}$ & 2.31 & 1.765 & 0.1650 & 1.70 & 1.80 \\
$\mathrm{~B}_{2} \mathrm{O}_{3}-\mathrm{Bi}_{2} \mathrm{O}_{3}-\mathrm{Al}_{2} \mathrm{O}_{3}$ & 2.25 & 1.785 & 0.1550 & 1.77 & 1.78 \\
$\mathrm{~B}_{2} \mathrm{O}_{3}-\mathrm{Bi}_{2} \mathrm{O}_{3}-\mathrm{ZnO}$ & 2.26 & 1.796 & 0.1455 & 1.65 & 1.70 \\
$\mathrm{~B}_{2} \mathrm{O}_{3}-\mathrm{Bi}_{2} \mathrm{O}_{3}-\mathrm{CdO}$ & 2.28 & 1.80 & 0.1498 & 1.90 & 1.80 \\
\hline
\end{tabular}

Also an LCR bridge (Hioki model 3031, Japan) was used to carry out the dielectric measurements. The samples were coated with silver coatings for obtaining good contact. The accuracy in the measurements of dielectric constant $\varepsilon^{-}$is $\sim \pm 0.001$.

\section{RESULTS}

The estimated values of the four parameters $\left(\chi_{1 \mathrm{av}}\right.$, $\alpha_{\mathrm{o}-2}, \mathrm{~A}, \mathrm{n}_{\text {calc. }}$ and $\left.\mathrm{n}_{\mathrm{m}}\right)$ are reported as follows Table 2 .

The refractive index has been determined according to the electromagnetic relationship $\left(n=\varepsilon^{1 / 2}\right)$.

\section{DISCUSSION}

With respect to the above data in Table 2, the concept of average electronegativity $\chi_{1 \text { av }}$ can be used to determine and predict the electronic polarizability of the oxideion for some ternary glasses. The new addition in our work is that, the equivalent fraction of each element of the glass system must be taken into the calculations of the average electronegativity. Equation 5 is more suitable to obtain $\alpha_{\mathrm{o}-2}$ through $\chi_{\text {glass }}$ for our samples under test. Accordingly Eq. 1 can reform as the following Eq. 9:

$\chi_{\text {3glass }}=\sum_{\mathrm{i}=1}^{\mathrm{N}} \frac{\mathrm{n}_{\mathrm{i}} \chi_{1}}{\mathrm{~N}} \mathrm{r}_{\mathrm{i}}$

where, $r_{i}$ is the equivalent fraction of each oxide including in the glass system.

Also the interaction parameter $\mathrm{A}$ is an important to describe the state of the total polarizability of the glass system.

The range of the glass formation in $\mathrm{B}_{2} \mathrm{O}_{3}-\mathrm{Bi}_{2} \mathrm{O}_{3}$ Mo system extends up to $5 \mathrm{~mol} \%$ and all the glass samples prepared are semi-transparent.
The dielectric constant $\varepsilon^{\prime}$, of glasses samples depends on electronic, ionic and dipole orientation contribution to the polarizability. The ionic polarizability arises from the displacement of ions of opposite sign from their regular lattice sites, resulting from the applied electric field, as well as from the deformation of the electronic shells, resulting from the relative of the ions. The behavior of $\varepsilon^{\prime}$ our system described may be attributed at low frequency to the polarizability arising from the contribution of multi components in the glassy system. As the frequency increases the ionic and orientation sources of polarizability decreases and finally disappear due to the inertia of the molecules and ions (Khor et al., 2009). The electronic polarizability $\alpha_{e}$ is the only process which follows the alternative fields at the visible spectrum. The ionic polarizability $\alpha_{i}$, contributes to the polarizability at high frequency. The space charge $\alpha_{\mathrm{s}}$ and $\alpha_{0}$ contribute to the polarizability of the suggested glass system at low frequency $(\sim 1000 \mathrm{~Hz})$.

Finally using the average electronegativity $\chi_{1 \mathrm{av}}$ and the estimated value of oxide ion polarizability $\alpha_{\mathrm{o}-2}$, the refractive index $\mathrm{n}_{\text {calc. }}$ has been evaluatedusing Eq. 7 with accurate method.

\section{CONCLUSION}

The average electronegativity has been estimated with more accuracy for the prepared samples of ternary glasses. It was found that there are a good correlation between the average electronegativity and the oxide ion polarizability as in the binary systems of glasses.

The refractive index can be determined or predicted using the concept of the average electronegativity and the electronic polarizability of the oxide ion for some ternary glasses as our samples.

\section{REFERENCES}

Chimalawong, P., J. Kaewkhao and P. Limsuwan, 2010. Optical investigation and electronic polarizability of $\mathrm{Nd}^{3+}$ doped soda-lime-silicate glasses. Energy Res. J., 1: 176-181. DOI: 10.3844/erjsp.2010.176.181

Dimitrov, V. and S. Sakka, 1996. Electronic oxide polarizability and optical basicity of simple oxides. I. J. Applied Phys., 79: 1736-1740. DOI: 10.1063/1.360962

Dimitrov, V. and T. Komatsu, 1999. Electronic polarizability, optical basicity and non-linear optical properties of oxide glasses. J. Non-Crystal. Solids, 249: 160-179. DOI: 10.1016/S00223093(99)00317-8 
Dimitrov, V. and T. Komatsu, 2010. An interpretation of optical properties of oxides and oxide glasses in terms of the electronic ion polarizability and average single bond strength. J. Univ. Chem. Technol. Metall., 45: 219-250.

Khor, S.F., Z.A. Talib, H.A.A. Sidek, W.M. Daud and B.H. Ng, 2009. Effects of $\mathrm{ZnO}$ on dielectric properties and electrical conductivity of ternary zinc magnesium phosphate glasses. Am. J. Applied Sci., $\quad 6$ : 1010-1014. DOI: 10.3844/ajassp.2009.1010.1014

Marquez, R. and C. Rinocon, 2006. On the dielectric constants of $\mathrm{A}^{\mathrm{I}} \mathrm{B}^{\mathrm{III}} \mathrm{C}_{2}{ }^{\mathrm{VI}}$ chalcopyrite semiconductor compounds. Phys. Status Solid, 191: 115-119. DOI: $10.1002 / p s s b .2221910112$

Reddy, R.R., Y.N. Ahammed, P.A. Azeem, K.R. Gopal and T.V.R. Rao, 2001. Electronic polarizability and optical basicity properties of oxide glasses through average electronegativity. J. Non-Crystalline Solids, 286: 169-180. DOI: 10.1016/S00223093(01)00481-1
Varshneya, A.K., 1994. Fundamentals of Inorganic Glasses. 1st Edn., Academic Press, Boston, ISBN10: 0127149708, pp: 570.

Vithal. M., P. Nachimuthu, T. Banu and R. Jagannathan, 1997. Optical and Electrical properties of $\mathrm{PbO}-\mathrm{TiO}_{2}$, pbO-TeO 2 glass system. J. Applied Phys., 81: 7923. DOI: 10.1063/1.365366

Zhao, X., X. Wang, H. Lin and Z. Wang, 2007. Correlation among electronic polarizability, optical basicity and interaction parameter of $\mathrm{Bi}_{2} \mathrm{O}_{3}-\mathrm{B}_{2} \mathrm{O}_{3}$ glasses. Phys. B: Condensed Matter, 390: 293-300. DOI: $10.1016 /$ j.physb.2006.08.047 